\title{
Best Practices of Russia and Finland in Extracting REE from Fertilizer Waste
}

\section{Vladimir Rychkov¹, Pertti Koukkari², Sergey Kirillov¹, and Evgenii Kirillov}

${ }^{1}$ Ural Federal University named after the first President of Russia B.N. Yeltsin, Ekaterinburg, Russia

${ }^{2}$ VTT - Technical Research Centre of Finland, Biologinkuja 7, Espoo. P.O. BOX 1000 FI-02044-VTT Finland

\section{Abstract}

In the production of fertilisers and commodity metals large amounts of stabilised waste is generated. Conventionally, manufacturing is targeted at the recovery of economically and technically most attractive key elements while the inorganic waste stream will gather all the other added-value chemical quantities. For example, substantial amounts of rare earth metals, which are increasingly used in various modern technologies including cleantech and photonics are present in phosphogypsum, the voluminous waste of the worldwide fertiliser industry. The waste heaps, while generally stabilised against weathering, appear usually granular or even as powder-like fines. Thus they represent a readily comminuted raw

Corresponding Author: Vladimir Rychkov; email: v.n.rychkov@urfu.ru

Received: 6 June 2017 Accepted: 9 July 2017

Published: 24 August 2017

Publishing services provided by Knowledge E

(c) Vladimir Rychkov et

al. This article is distributed under the terms of the

Creative Commons

Attribution License, which permits unrestricted use and redistribution provided that the original author and source are credited.

Selection and Selection and Peer-review under the responsibility of the Technogen Conference Committee.

\section{G OPEN ACCESS} material for innovative mechanical, hydrometallurgical, biohydrometallurgical and pyrometallurgical techniques to recover considerable amounts of valuable metals and metal concentrates.

Keywords: phosphogypsum, fertilisers hydrometallurgy, rare earth metals, leaching, sorption, anaerobic, sulphides

\section{Introduction}

Phosphogypsum ( $\mathrm{CaSO}_{4}{ }^{*} 2 \mathrm{H}_{2} \mathrm{O} ; \mathrm{PG}$ ) heaps exist in over 50 countries, the annual stockpiling exceeding $200 \mathrm{Mt}$ worldwide (exact figures are difficult to gain as, e.g., statistics in large Asian countries are not available). Russia has compiled $250 \mathrm{Mt}$ and every year produces $4 \mathrm{Mt}$, in Finland the PG stacks exceed $50 \mathrm{Mt}$ altogether with $1.5 \mathrm{Mt}$ annual increase. In the fertilizer manufacturing process even $80 \%$ of the RE will end up in the phosphogypsum side product, which then holds from 0.2 to 0.4 w$\%$ REE. Thus the content of REE in each PG stack may vary. In Russia, the average is given as $0.4 \%$ while in Finland the content is lower ( $0.17 \%)$ due to the igneous phosphate rock used in the fertilizer process. Recovery of the REE from such piles yet would allow a considerable production volume reaching to 10-15 $000 \mathrm{t} / \mathrm{yr}$ of REE. 


\section{Results and Discussion}

\subsection{Recovery of REE from Phosphogypsum with Solid Ion Exchanging Adsorbent}

Rare earth elements (REE) are as well classified as EU critical metals. The Finnish apatite minerals, industrially utilized for manufacturing phosphate fertilizers represent a potential secondary source of REE. In the current fertilizer manufacturing process even $80 \%$ of the REE will end up in the phosphogypsum (PG) side product, which then holds $0.15-0.5 \%$ of REE (Table 1 ). So far economical means of recovering REE from apatite or PG have not been found. Novel active extraction or ion exchange methods as well as innovative biochemical methods have been recently examined by VTT and its co-operation partners.

In the conventional processing of Rare Earth Elements (REE) from dilute saline solutions containing large amounts of $\mathrm{Fe}, \mathrm{Al}$ and other elements are typically formed. The extraction of REE then becomes an elaborate task to be solved by traditional hydrometallurgical methods. For example in the industrial scale the recovery of REE from these solutions is traditionally conducted via deposition by ammonia, alkalis and anions such as $\mathrm{F}^{-}, \mathrm{S}_{2} \mathrm{O}_{4}^{2-}$, and $\mathrm{PO}_{4}^{3-}$. Disadvantages of these methods include, e.g., a large loss of REE (20-25\%) as coprecipitating hydroxides with metals such as Fe (III), $\mathrm{Al}, \mathrm{Zr}$ and $\mathrm{Ti}$. The waste waters caused by the large flow rates, chemicals used for precipitation and low regeneration rates can cause challenges.

Sorption and extraction are currently the most promising methods for extracting REEs from dilute solutions, since they have a high-performance and simple hardware design. They are also selective and well suitable for construction of closed circulation. Yet, even in such processes, the maximum extraction efficiency has appeared as a challenge [1]. At Ural Federal University REE from phosphogypsum have been recovered by counter current acidic sorption leaching as described in Figure 1. With the data received from the authors, a multicomponent process model has been developed at VTT [2].

With sulfuric acid leaching and commercial cationites as sorbents extraction efficiency of $60-65 \%$ has been gained. The respective minipilot has been operated continuously to process a batch of 45 tonnes PG. The REE concentrate obtained was ca $100 \mathrm{~kg}$ 's with $48-54 \%$ of rare earth elements.

Desorption was carried out with a solution of ammonium sulphate. The choice of this reagent was dictated by the fact that further processing of the eluates will involve the use of ammonia and ammonium salts to precipitate concentrates. Ammonium ions also have a good desorbing capability because of the affinity to cation binding 


$\begin{array}{ll}\begin{array}{l}\text { Component in phosphogypsum } \\ \left(\mathrm{CaSO}_{4} \cdot 2 \mathrm{H}_{2} \mathbf{0}\right)\end{array} & \text { [\% mass] } \\ \mathrm{CaO} & 32.5 \\ \mathrm{SO}_{3} & 44.0 \\ \mathrm{P}_{2} \mathrm{O}_{5} & 0.65 \\ \mathrm{~F} & 1.2 \\ \mathrm{SiO}_{2} & 0.5 \\ \mathrm{Fe}_{2} \mathrm{O}_{3} & 0.1 \\ \mathrm{Al}_{2} \mathrm{O}_{3} & 0.1 \\ \mathrm{MgO} & 0.1 \\ \mathrm{H}_{2} \mathrm{O} \text { (cryst.) } & 19.0 \\ \Sigma \mathrm{REE} & 0.15-0.4\end{array}$

TABLE 1: Composition of phosphogypsum.

functional groups in the adsorbent resin. To further refine the desorbed REE solution it was treated with $10 \% \mathrm{NH}_{4} \mathrm{OH}$. Pre-neutralization of the excess acidity with ammonia was necessary, firstly, to help reduce the formation of ammonium carbonate salts, and secondly, to precipitate bulk metal hydroxides such as $\mathrm{Fe}^{3+}, \mathrm{Al}^{3+}$ simultaneously sorbed with REE. Precipitation led to $\mathrm{pH}$ 4.5-5. This interval is characterized by the end of the precipitation of hydroxides of the above metals. Precipitation of REE as carbonates is a well-known process and can be performed by use of ammonium carbonate. With this treatment, a recovery rate of $75-80 \%$ of REE as $\mathrm{Ce}_{2} \mathrm{O}_{3}$ and light and heavy REM carbonate concentrates has been achieved with purity exceeding $99 \%$ when up to 50 kg's of original REE concentrate solution has been treated.

\subsection{Passive Treatment of Phosphogypsum with Sulphate Reducing Bacteria (SRB)}

The use of sulphate reducing bacteria (SRB) for removing contaminants such as heavy metals from aqueous solutions is well known. The SRB can be used for treating groundand surface waters contaminated with acid mine drainage (AMD), and for recovering metals from wastewater and process streams. The biologically produced $\mathrm{H}_{2} \mathrm{~S}$ precipitates metals as metal sulfides, while biogenic bicarbonate alkalinity neutralizes acidic waters. In such method, the aqueous sulphate solution, provided with appropriate electron donor (either hydrogen or organic compound) is

inoculated with micro-organisms, such as Desulfovibrio bacteria, which promote the reduction of the sulphate ion to hydrogen sulphide:

$$
8 \mathrm{H}_{2}+2 \mathrm{SO}_{4}^{2-} \longrightarrow \mathrm{H}_{2} \mathrm{~S}+\mathrm{HS}^{-}+5 \mathrm{H}_{2} \mathrm{O}+3 \mathrm{OH}^{-}
$$



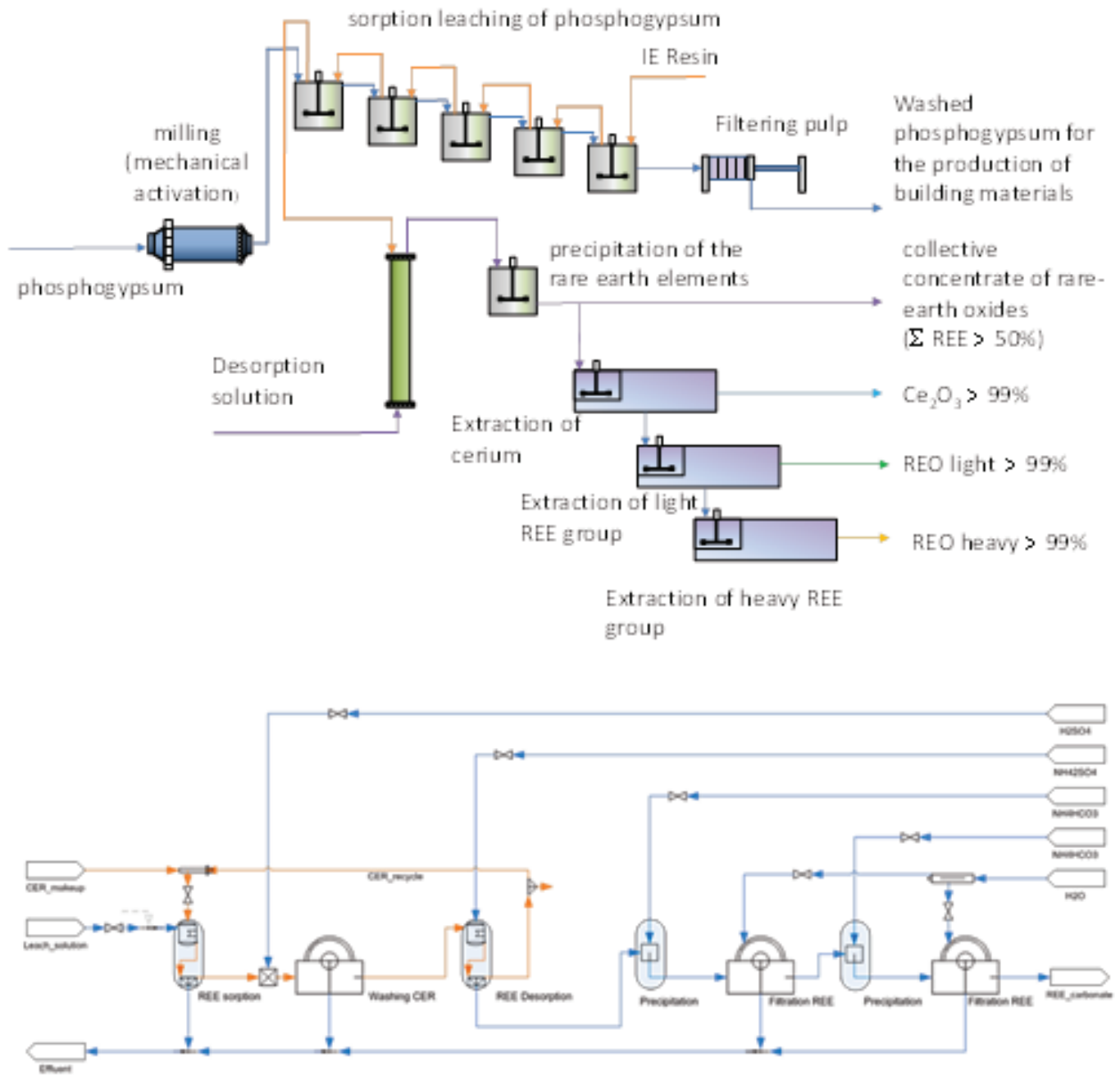

Figure 1: The technological scheme of countercurrent REE recovery from PG (above). Flowsheet process model of the countercurrent sorption process (below).

Instead of hydrogen, organic compounds descending from e.g. fermentation processes or waste streams with anaerobic degradation stages and including e.g. organic acids or alcohols can be used as electron donors. One may expect the SRB sulphide sludge to contain large fraction of the REM sulphides as a finely dispersed precipitate. The SRB sludge containing the insoluble REM (sulphides) will have high magnetic susceptibility and could be recovered from the bio-sludge by physical separation with a recently patented concept [3].

Preliminary results achieved by aqueous PG leachate amended with yeast extract and lactate donor using Desulfovibrio desulfuricans and mixed cultures are presented in Table 2.

The result indicates substantial enrichment of rare earth metals in the formed SRB precipitate. New research (REE-PG) will pursue to enhanced volumetric efficiency of 


\begin{tabular}{|l|l|l|} 
& PG & SRB \\
\hline La [ppm] & 390 & 30400 \\
\hline Ce [ppm] & 1100 & 66200 \\
\hline Y [ppm] & 23 & 8800
\end{tabular}

TABLE 2: REE enrichment into precipitate from PG by sulphate reducing bacteria (SRB).

the SRB based technique. SRB strains such as Desulfovibrio, Desulfobulbus and Desulfotomaculum will be isolated from environmental samples and cultivated, and their activity in different media containing PG sludge will be tested. The research to be commenced in 2016 will be conducted by VTT in co-operation with MINTEK biohydrometallurgical division as part of the REE-PG project led by Lappeenranta University of Technology and funded by Academy of Finland (Finland-South Africa co-operation).

\section{Conclusion}

The inorganic waste heaps being compiled in large volumes in the metallurgical and fertilizer industries provide both environmental challenge in their storage and a potential urban mine having the "concentrate" already in a ready processed form for recycling their contents. Thus in environmentally conscious world striving for available sources of precious and critical metals the waste stacks appear as a rewarding target. The objective is to find means to reduce or remove the environmental footprint of problem waste storage and to find technically and economically viable means to recover their value-added contents. Jarosite and phosphogypsum are among the foremost examples of such utilization.

For the phosphogypsum processing, the treatment by countercurrent absorption allows the recovery of valuable rare earth metals. A more further off concept could be provided by the biological treatment, where absorption steps would then be replaced by bacterial activity and adjacent physico-chemical fractionation. While the biochemical method has yet to be scaled up from small laboratory scale, the absorption technique is attested robust, combining the best practices of resin-inleach and conventional selective precipitation techniques. The operated minipilot appears as 'proofof-concept' while giving fractionated REE concentrates. The economic operation of the rather complex process will depend on demand and price levels of rare earth applications. Yet, with their wide range of established uses in new energy techniques, mobile electronics, lasers, lighting and photonics, power transmission etc. the global demand most likely will but increase.

PG treatments rely mostly on unit processes, whose technical feasibility has been proven in many applications before. Thus, with appropriate references gained in the 
ongoing research, the concepts can also be copied to treat the multiple similar sources around the globe.

\section{Acknowledgements}

Academy of Finland: Grants nr 298094, 303453, 303454 Raw Matters Finland Infrastructure (RaMl).

Ministry of Education and Science of Russian Federation: 14.581.21.20002

\section{References}

[1] V. Yahorava, V. Bazhko, G. Khosa, A. du Preez, and R. Mottay, 2012, Recovery of rare earths from phosphogypsum: development of the flowsheet up to refinery.

[2] S. Kirillov, Y. Kirillov, R. Pajarre, V. Rychkov, and P. Koukkari, Recovery of Rare Earth Elements and Scandium as Side Products of Uranium and Phosphate Mining, Konferens i Mineralteknik, vol. 2.- 3.2, Sweden, Lulea, 2016.

[3] P. Koukkari, J. Mäkinen, M. Bomberg, A. Lehtonen, M. Arnold, and J. Mäkinen, "Method for recovering rare earth metals from waste sulphates," FI B, Article ID 125550, pp. 30-11, 2013. 